\title{
Correction to: Association of Depressive Symptoms with Lapses in Antiretroviral Medication Adherence Among People Living with HIV: A Test of an Indirect Pathway
}

\author{
Jacklyn D. Babowitch ${ }^{1}$. Alan Z. Sheinfil ${ }^{1}$ Sarah E. Woolf-King ${ }^{1} \cdot$ Peter A. Vanable $^{1}$ · Shannon M. Sweeney ${ }^{1}$
}

Published online: 31 May 2018

(c) Springer Science+Business Media, LLC, part of Springer Nature 2018

\section{Correction to: AIDS Behav \\ https://doi.org/10.1007/s10461-018-2098-1}

The original version of this article unfortunately contained a mistake in Fig. 1. The figure was incorrectly presented with the results of an additional path model for forgotten antiretroviral therapy (ART) doses that was dropped from the primary analyses.

A

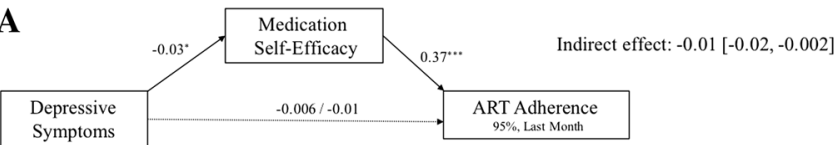

C

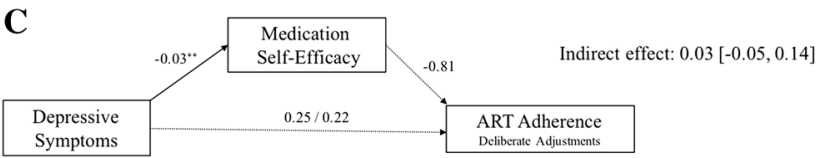

Fig. 1 Path model for the association of depressive symptoms to antiretroviral medication adherence with the indirect association of medication self-efficacy modeled. Covariates were not included in
The corrected Fig. 1 which is presented with this erratum contains four path models for each of the primary outcome variables: 95\% adherence in the last month, self-reported detectable viral load, deliberate adjustments to ART regimen and skipped ART doses.

The correct figure is given below.
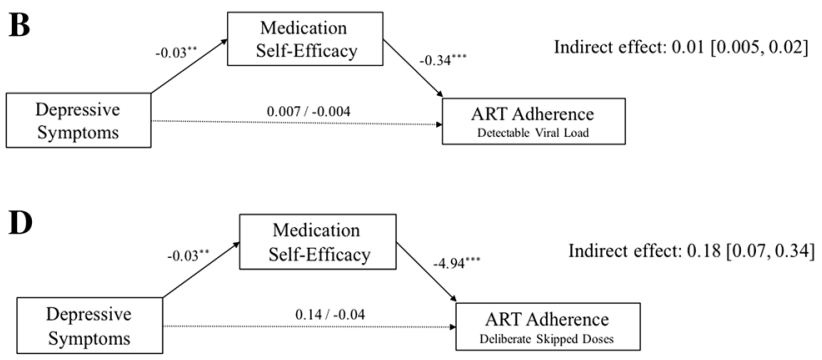

the figure for simplicity. Unstandardized path coefficients are shown. Significant paths are shown as solid lines. ${ }^{*} p<0.05$; ${ }^{*} p<0.01$; $* * * p<0.001$
The original article can be found online at https://doi.org/10.1007/ s10461-018-2098-1.

Jacklyn D. Babowitch

jdbabowi@syr.edu

1 Department of Psychology, Syracuse University, 430

Huntington Hall, Syracuse, NY 13224-2340, USA 